\title{
An environmental renovation strategy based on adaptive control optimisation of a modular light regulating façade system
}

\author{
A. G. Michael, K. C. Alexandrou, P. G. Konatzii \& A. K. Kalli \\ Department of Architecture, University of Cyprus, Cyprus
}

\begin{abstract}
The design of building envelopes, and in particular reactive facades, has shown a rapid growth, engaged in an increasing amount of applications in contemporary architecture. Recent developments in adaptive building skins have clearly shown their potential on effectively handling and optimising multiple energy performance issues through their enhanced responsive behaviour characteristics. In the meantime, the design outcome has been acknowledged in many cases, and exhibited great growth on many architectural aspects, by related means of environmental, functional and aesthetic optimization. In this frame, such systems have a great prospect of establishing a high efficiency renovation strategy of the existing building stock in Europe. This strategy may apply to both aged-buildings and contemporary highly-glazed buildings, aiming at their environmental renovation, by eliminating extensive use of artificial illumination in the indoor spaces. In this framework, the present paper proposes a re-active prototype facade system, responsible for dealing with lighting regulation of indoor spaces. The research focuses on achieving comfortable natural lighting levels and uniform lighting distribution along the indoor space of a typical office space. Parametric associative design logic has been employed to assist the kinetic simulation of the transformable skin facade. A series of real-time lighting performance analyses describe the fluctuations of lighting levels and uniformity factor of the space under study, according to the kinetic transformation of the adaptive façade system. Conclusively, this paper discusses the results obtained and further control optimisation potentials of the system, towards a more efficient daylighting regulation.

Keywords: adaptive building skin, natural lighting levels, uniformity daylighting factor, parametric design, dynamic simulation analysis.
\end{abstract}




\section{Introduction}

The operational energy consumption rates of the built environment, in the European context, have a central position in current discussions, as the built environment is highly energy dependent. Amongst all energy consuming sectors in Europe, the building sector occupies an amount of $40 \%$, due to its low energy performance capabilities [1]. Within the building sector itself, non-residential buildings account for $25 \%$ of the building area, out of which $23 \%$ belongs to office departments, i.e. private and public office buildings. The energy consumption of office buildings reaches the astonishing amount of $26 \%$ compared to all other building uses $[2,3]$. An isolated examination of the energy consumption for an entire year reveals that artificial lighting is responsible for the consolidating amount of $16 \%$ of the overall energy consumption [1]. In many situations, low day-lighting levels and, consequently, the extensive use of artificial lighting in the building sector, are directly associated with unsuitable architectural design decisions [4]. Moreover, highly glazed skins, used in many contemporary buildings, result in limited visual comfort. This is due to direct unfiltered sunlight which causes excessive contrasts and thus glare issues. Glare issues lead to the permanent use of internal blinds, or other internal shading solutions, and consequently to extensive use of artificial lighting. Moreover, in the case of highly glazed facades, direct solar gains constitute the main negative parameter for high cooling demands during the summer period, highlighting the need for external shading devices for solar protection and reduction of energy consumption. As a matter of fact, an external adaptive shading façade can deal both with the issue of solar protection and glare issues, leading towards improved indoor conditions in terms of thermal comfort and natural lighting performance $[5,6]$.

The existing office building stock in Europe, mainly built during the decades of the 1960s and 80s, can be described as unsuitable in terms of reliability and energy efficiency. Although many office buildings of that period have wellorganized spatial configurations, based on the typologies of the Modern Movement in architecture, they do not hold any special architectural value worthy of conservation in its original state. In this respect, the possibility of the replacement of a large part of Europe's existing building stock is likely to take place, as an attempt to upgrade the quality of the built environment. It is generally recognised that the replacement of buildings has a negative ecological impact; moreover, it entails removal and relocation of the occupants during the construction period. An alternative to building replacement or conventional renovation methods, is prosthetic renovation i.e. addition of a new lightweight plug-in adaptive layer in the building façade, which entails a limited ecological impact. Additionally, the intervention is performed exclusively on the outside of the building and thus, the renovation process allows the unobstructed use of indoor spaces [7].

In this framework, it becomes evident that further research is needed for the optimization of indoor lighting conditions and thermal comfort of the existing building stock. A number of research articles suggest that goals may be achieved through the application of technologically advanced systems on the building 
facades, i.e. kinetic shading systems, solar energy production devices, high performance protective membrane systems, or other innovative technologies [810]. In the case of kinetic shading systems, these applications relate to integrated computation or intelligent control systems, which enable passive and active adaptive behaviours. In most cases, solar radiation regulation systems are lightweight, modular systems of identical elements, following a standardized construction and easy assembly procedure.

Contrary to passive shading methods, systems with kinetic properties are described by dynamic adaptive behaviour, they are able to handle complex issues, such as external environmental conditions adaptation, as well as to satisfy the occupant's needs, in terms of visual permeability or aesthetic pleasure. Their adaptability allows kinetic facades to configure differentiated geometrical patterns according to the desired need or purpose $[11,12]$. Al Bahar Towers in Abu Dhabi, design by AHR Aedas Architects, is an example of installed devices in existing buildings that demonstrates how modular components with kinetic mechanisms reduce glare, improve daylight penetration, eliminate reliance on artificial lighting and produce over $50 \%$ of the buildings' energy requirements through solar gain [13]. Specifically, the controllable umbrella-like units installed, open and close completing a daily cycle which responds to the sun's position, supported by linear actuators and a central real-time processing system. Similar kinetic façade systems that serve an automatic control of the interior lighting and heating conditions are also found in buildings that use embedded computation for a solar radiation treatment, used in the initial design process such as AVAX S.A. Headquarters in Athens, designed by A.N. Tombazis and Associates Engineers and ThyssenKrupp Quarter in Essen, designed by JSWD Architekten + Chaix \& Morel et Associés. The system was integrated in AVAX S.A. Headquarters comprises of vertical louvers with automated rotation mechanisms in order to control insolation, contributing to lighting uniformity and possible glare effects avoidance [14]. In the case of Thyssen Krupp Quarter, the system incorporates kinetic triangular louvers which achieve significant lighting quality improvements while they create an interesting visual exterior through adjusting its geometrical design [15]. It is clear that implemented examples of kinetic façade systems show how dynamic lighting treatment systems could, directly and indirectly, benefit the users and the overall ecological and architectural impact of buildings.

The integration of kinetic systems with adaptive behaviour in a building's façade, within the framework of a prosthetic renovation plan, may be a sustainable strategy for avoiding costly and time consuming renovation procedures. The manufacturing and construction phase of such systems could result in minimal costs compared to other methods of renovation and could upgrade the architectural aesthetic of the building and its surrounding environment $[16,17]$.

According to the above mentioned parameters and criteria, a kinetic modular façade system, that takes the role of a plug-in design solution, is proposed in the present paper, investigating its ability to sustain a constant visual comfort, and perform a flexible adjustable behaviour to enable uniform light distribution across the selected space boundaries. Emphasis is placed on the reservation of appropriate 
natural lighting level conditions, the avoidance of glare issues, as well as on quantitative assessment of the system's behaviour.

\section{Design methodology}

The design development and analysis process of the kinetic skin is formulated under a parametric associative design logic framework, and real-time lighting performance analysis platform. Both the examined space dimensions and the geometrical transformation of the system are parametrically defined. This option is selected to provide a full and accurate control of the geometrical transformation of the proposed skin, allowing, at the same time, the generation of a design platform that can handle a multi-parametric investigation strategy easily, inside a single graphical environment. The parametric plug-in Grasshopper $3 \mathrm{D}^{\circledR}$ (plug-in of Rhinoceros 3D) was used to control the geometrical interdependencies of the system's geometrical components, according to the correlations that govern such generation. Grasshopper's additional features, contained in Honeybee + Ladybug plug-in, are responsible for creating a direct link with Desktop Radiance ${ }^{\circledR}$ for the lighting analysis calculations. All results are obtained and visualised in the graphic environment of Rhinoceros $3 \mathrm{D}^{\circledR}$.

\subsection{Case studies}

For the selection of a representative case study, an investigation in relation to the typologies of existing office building stock, constructed between the 1960s and $80 \mathrm{~s}$ in different European countries, was performed. Based on this, the most common plan configuration observed is the combination of a horizontal access corridor with its corresponding vertical office spaces, usually having their smaller side facing the exterior opening. The average dimensions of the working spaces are approximately around $4 \mathrm{~m} \times 8 \mathrm{~m}$.

\subsection{System description and control}

The basic design principles for light treatment led to a system of customized multidirectional moveable modules, which allow the formation of variable geometrical patterns. The analysed space has dimensions of $4 \mathrm{~m}$ width by $8 \mathrm{~m}$ depth and $3.2 \mathrm{~m}$ height. The south-facing elevation of the model is covered by a full plane glazed surface placed at a distance of $0.6 \mathrm{~m}$ inwards since the kinetic system is placed on the edge of the same elevation of the model. The proposed skin is constructed on the basis of a grid of $10 \times 12$ modular units, resulting in 48 planar units of $0.32 \times 0.32 \mathrm{~m}$ in dimensions. All units are enhanced by a $180^{\circ}$ of freedom in rotation, in both $\mathrm{X}$ and $\mathrm{Z}$ axis. The rotation centre is consigned to the mid-plane point of each unit separately and all units can handle the same transformation at a time (fig. 1).

The digitally generated model was associated with weather data for the location of Larnaca, Cyprus, which has latitude of $34,88^{\circ}$ and longitude of $33,63^{\circ}$ (downloaded from http://www.energy.gov/). At a preliminary stage, the kinetic skin was geometrically correlated with the sunlight vector forcing it to follow a rotation that results in constant perpendicular inclination at a three-dimensional 
level. At a further stage, the modular skin was assigned to further manual control of additional rotation, in steps of $10^{\circ}$, in both $\mathrm{X}$ and $\mathrm{Z}$ axis. This supplementary kinetic control of the system serves to quantitatively assess comfortable daylighting level and day lighting uniformity across the indoor space.
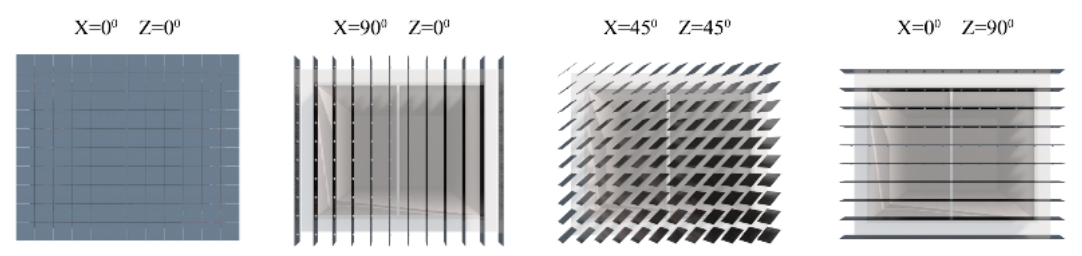

Figure 1: Kinetic flexibility of the modular skin.

To avoid direct solar insolation entering the space, a secondary real-time sunlight simulation was performed in order to set the rotational limitation of the kinetic skin (fig. 2). This constraining function limits full range rotation of the movable elements up to a permissible level, in order to avoid glare issues, i.e. excessive contrast effects.
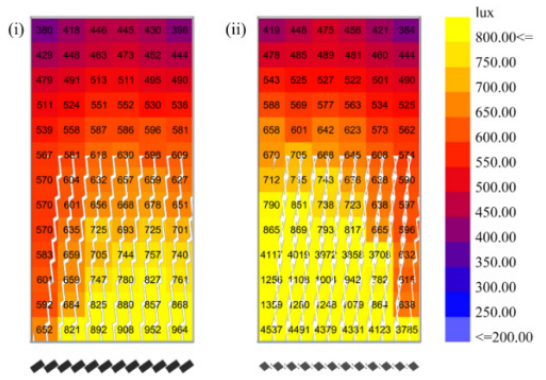

Figure 2: Direct sunlight setting the rotational limitations of the system.

The system is further examined to compare the most preferable configuration that corresponds to the optimum lighting performance outcomes (fig. 3).

\subsection{Lighting analysis and assessment factors}

The generated geometry was linked with Honeybee + Ladybug plug-in for Grasshopper, which is responsible to execute lighting analysis calculations using external analysis engine, i.e. Desktop Radiance version 2.0 Beta, and then retrieve the results back to the Grasshopper-Rhinoceros 3D environment. The model was oriented with the kinetic system facing South. The south facing surface of space was defined as a conventional glazing surface, designated as a Double Glazed Low E glass material with a visible transmittance of R: $0.7, \mathrm{G}: 0.8, \mathrm{~B}: 0.8$. For the skin tiles, aluminium material of R: $0.65, \mathrm{G}: 0.65, \mathrm{~B}: 0.65$ reflectance was used. Additionally, surface roughness was set to $0.02(0=$ perfectly smooth, $0.5=$ perfectly rough) and specularity to 0.5 , in order minimise mirror effects and rather 
work as a light diffuser. All other indoor surfaces of space were treated as conventional wall finishing material, with colour properties of 0.9 RGB reflectance value ( 1 equals to 255 ). The bottom surfaces of the space were assigned to floor materials set to R: $0.6, \mathrm{G}: 0.4, \mathrm{~B}: 0.2$ reflectance values with increased specularity (up to 5). All defined geometries were accurately defined to form a totally ceiled space. The analysis grid is divided by $13 \times 6$, resulting in 78 square tiles of $0.4 \times 0.4 \mathrm{~m}$ side dimension, located $75 \mathrm{~cm}$ above floor level in order to record results at the height of an office desk. The luminance level on the analysis grid scales from the lowest $\geq 200$ Lux to highest 800 Lux with an interval of 50 lux (fig. 3).

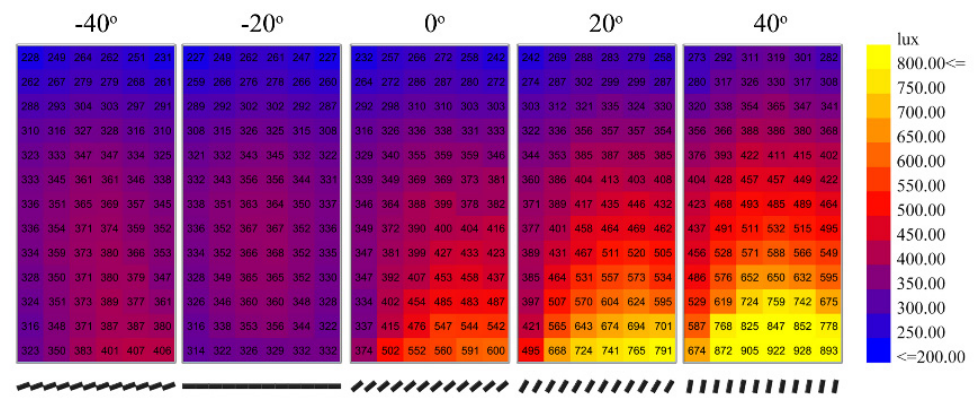

Figure 3: Lighting analysis for system's rotation on $\mathrm{Z}$ axis on December 21 st 09:00.

In each configuration system position under study, the percentage of the area of the plan that exceeds 500 Lux is recorded as a validating coefficient for the luminance comfort inside the room. The preferable conditions supporting the efficient functionality of the office space are defined by the percentage of the area of the plan that exceeds 500 Lux and the uniformity daylight factor i.e. UDF, expressing the homogeneity level of lighting distribution, defined by the singular minimum Lux value divided by the average value of the entire plan, i.e. UDF $=$ $\mathrm{DF}_{\text {min }} / \mathrm{DF}_{\text {mean }}$. According to the assessment method for sustainable buildings BREEAM 2.08, the required uniformity daylight factor (UDF) for achieving an efficient working environment should be at least 0.4 [18].

\section{Results and discussion}

In order to evaluate the system's performance, a number of different studies were performed. Initially, a set of results were exported to assess the overall performance of the system and express the values of the analysis grid of the automatic adjustments of the system, i.e. perpendicular to the sun's vector, at the 21 st day of each month of a year. In a second phase, the study concentrates on specific characteristic dates of the year i.e. summer solstice on June 21st, winter solstice on December 21st, spring and autumn equinox on March 21st and September 21 st respectively, analysed at three different hours of the day, i.e. 09:00 $\mathrm{h}, 12: 00 \mathrm{~h}$ and15:00 $\mathrm{h}$, thus obtaining nine quantitative results. The 
optimum lighting performance results, in terms of lighting levels and uniform lighting distribution, achieved through the adaptive façade system's modular unit's rotation on $\mathrm{X}$ and $\mathrm{Z}$ axes, for characteristic days of the year and hours of the day, presented in aggregated form in fig. 4. On a further, third phase, each of the nine already collected upshots were examined according to the system's transformability in both, $\mathrm{X}$ and $\mathrm{Z}$, axes. For example, on 21st September at 09:00 h (i.e. $\mathrm{H}: 55.5^{\circ}$, A: $-9.4^{\circ}$ ) modular units rotated between $+30^{\circ}$ and $-40^{\circ}$ in $\mathrm{X}$ direction and between $+10^{\circ}$ and $-50^{\circ}$ in $\mathrm{Z}$ direction. Within these constrained values, the system prevents direct solar gains and thus minimizes the possibilities for glare issues.

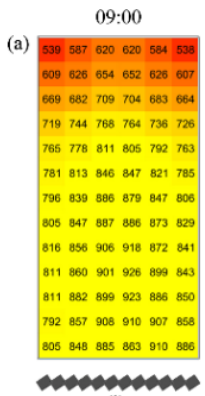

(i)

(b)

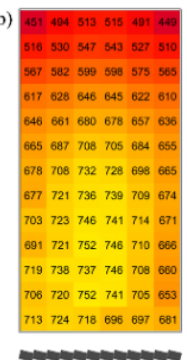

(i)

(c)

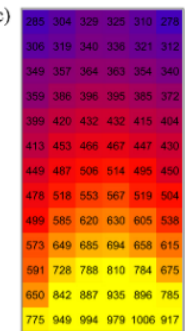

IIIIIIIII

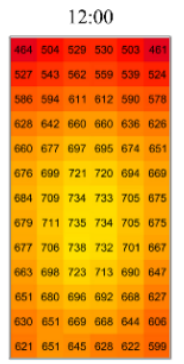

(ii)

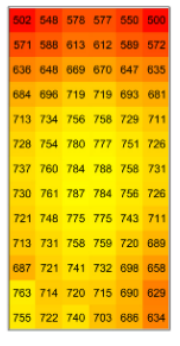

(ii)

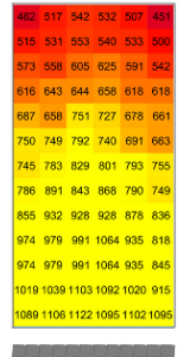

(ii)

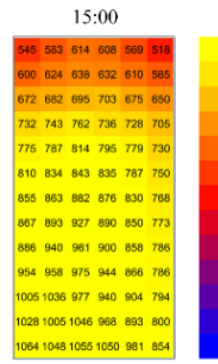
lux $800.00<$ 750.00

700.00

650.00

600.00

550.00

550.00
500.00

50.00

400.00

350.00

300.00

250,00

$<=200.00$

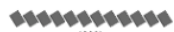

(iii)

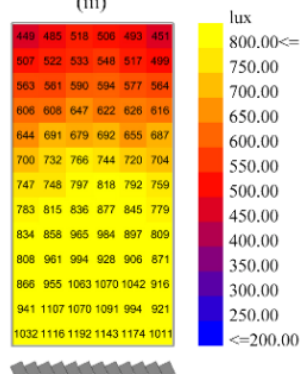

(iii)

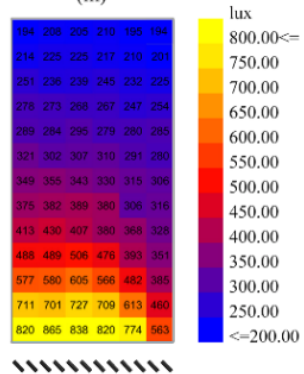

(iii)

Figure 4: System's optimum lighting performance results in (a) June 21st, (b) September 21st and (c) December $21 \mathrm{st}$ at (i) 09:00 h, (ii) 12:00 h, (ii) 15:00 h. 
Regarding the first set of results, the calculations of the automatic adjustments of the system on the $21 \mathrm{st}$ day of each month of a year at 12:00 $\mathrm{h}$ are recorded in fig. 5. The graph reveals a comparative lighting performance for the space under study according to the percentage of the plan area in which the daylight levels exceed 500 Lux and the uniformity daylight factor, UDF. The results show the positive contribution of the light regulation system during the entire year. More specifically, during the period from February to October, the system succeeds in maintaining daylight levels for $99 \%$ of the plan area higher than 500 Lux and simultaneously manages to stabilize the uniformity daylight factor, UDF around 0.7. During the months of November, December and January, the percentage of the plan area with daylight levels higher than 500 Lux decreases to $86 \%, 85 \%$ and $77 \%$ respectively, as a result of lower external natural lighting levels during the winter months. Nevertheless, this primary investigation demonstrates the potential of the modular system under study, leading to a more detailed analysis of its performance in the following stages.

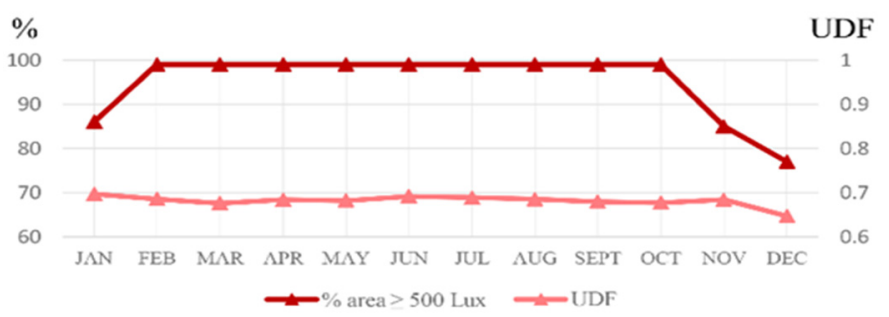

Figure 5: Lighting performance for the automatic adjustments of the system on an annual basis i.e. the 21 st day each month at 12:00 h.

The second and third sets of study results concentrate on characteristic days of a year, i.e. solstices and equinoxes. As shown in fig. 6, at 09:00 h of the summer solstice on 21 st June, the results of the reference configuration record a percentage of $99 \%$ of the plan exceeding 500 Lux and a uniformity day lighting factor UDF at 0.641 , expressing high lighting conditions and good distribution across the plan area, evidently supported by the external high natural lighting levels during the period under study. A rotation of the modules in $\mathrm{Y}$ axis at $-50^{\circ}$, additionally to the reference configuration of the modules, maintains the calculation of lighting levels above 500 Lux at $99 \%$ and raises the uniformity daylight factor UDF at 0.675 , thus further supporting functional efficiency and visual comfort. At 12:00 h, the simulation results exceed 500 Lux at $99 \%$ of the plan area, without decreasing after further rotations, while achieving to increase the uniformity daylight factor UDF from 0.696 of the reference configuration up to 0.712 with a further rotation of $+50^{\circ}$ in $X$ axis, which is indeed the optimum configuration. Similarly, at 15:00 h of the same day, the percentage of the plan area exceeding 500 Lux remains at $99 \%$ during all rotations of $\mathrm{X}$ and $\mathrm{Z}$ axes and the uniformity daylight factor UDF is highest at the rotation of $+30^{\circ}$ in $\mathrm{Z}$ axis, achieving a factor of 0.628 compared to 0.595 of the reference configuration, offering the best possible lighting conditions for that specific time of the day. 


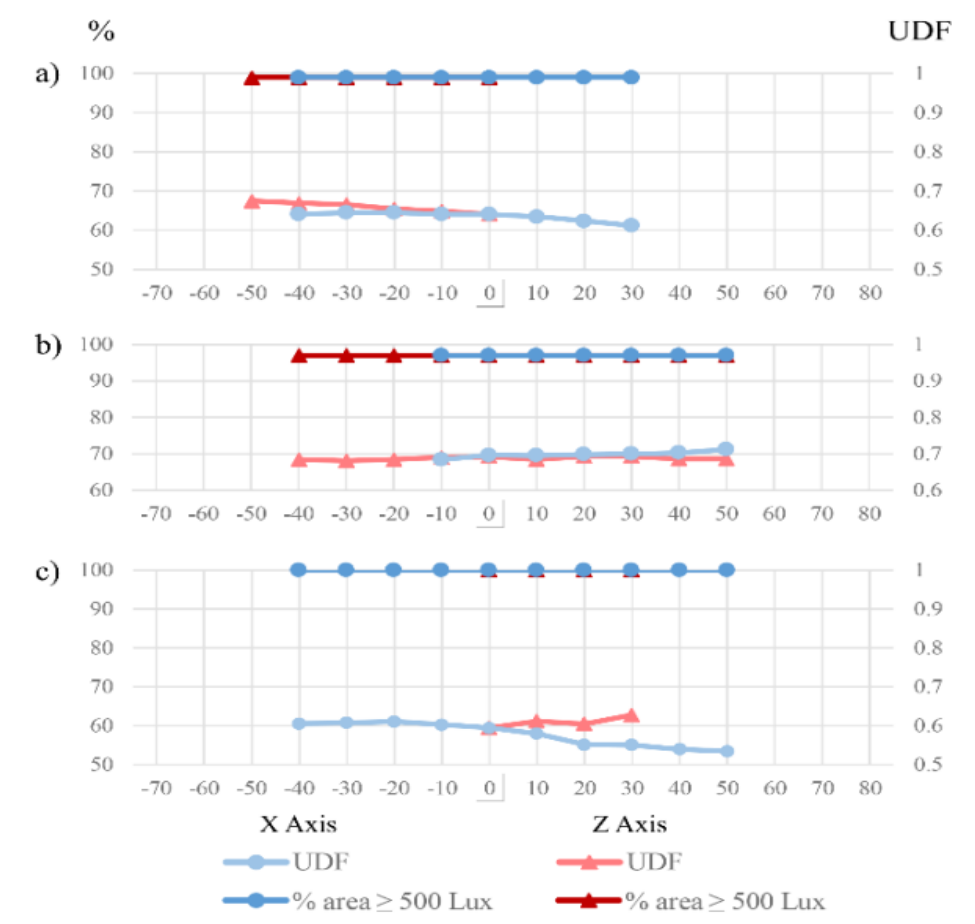

Figure 6: Lighting performance on June $21 \mathrm{st}$ (a) 09:00 h, (b) 12:00 h, (c) $15: 00 \mathrm{~h}$.

Following the same quantitative criteria for evaluating daylighting performance, fig. 7 demonstrates the analysis results during the equinox of September 21st. At 09:00 h, the reference configuration supports a relative lighting performance achieving a $99 \%$ of the plan area over 500 Lux and a uniformity daylighting factor UDF of 0.628 . Furthermore, the rotation of $-70^{\circ}$ in $\mathrm{Z}$ axis yields a better lighting condition since it increases the uniformity factor at 0.671 , although it causes a slight decrease of the Lux across the plan at 95\%, which still keeps within an optimized situation. At 12:00 h, the percentage of the plan area exceeding $500 \mathrm{Lux}$ is recorded at $99 \%$ of all positions. The most efficient condition is recorded at the arrangement of $+40^{\circ}$ rotation in $\mathrm{X}$ axis achieving a uniformity daylighting factor UDF of 0.71 . During the same days at 15:00 h, the reference configuration yields a percentage of $88 \%$ exceeding 500 Lux and a uniformity factor of 0.545 . Although this arrangement ensures efficient lighting levels across the space, a further rotation of $-40^{\circ}$ in $\mathrm{X}$ axis causes an increase at $96 \%$ and 0.568 for the percentage and uniformity factors respectively and thus, achieves a comparatively more efficient lighting condition for this time of the day during the autumn equinox.

The last part of the results (shown in fig. 8), refers to the winter solstice on December 21st, and reveals the calculations of the system during the period with 


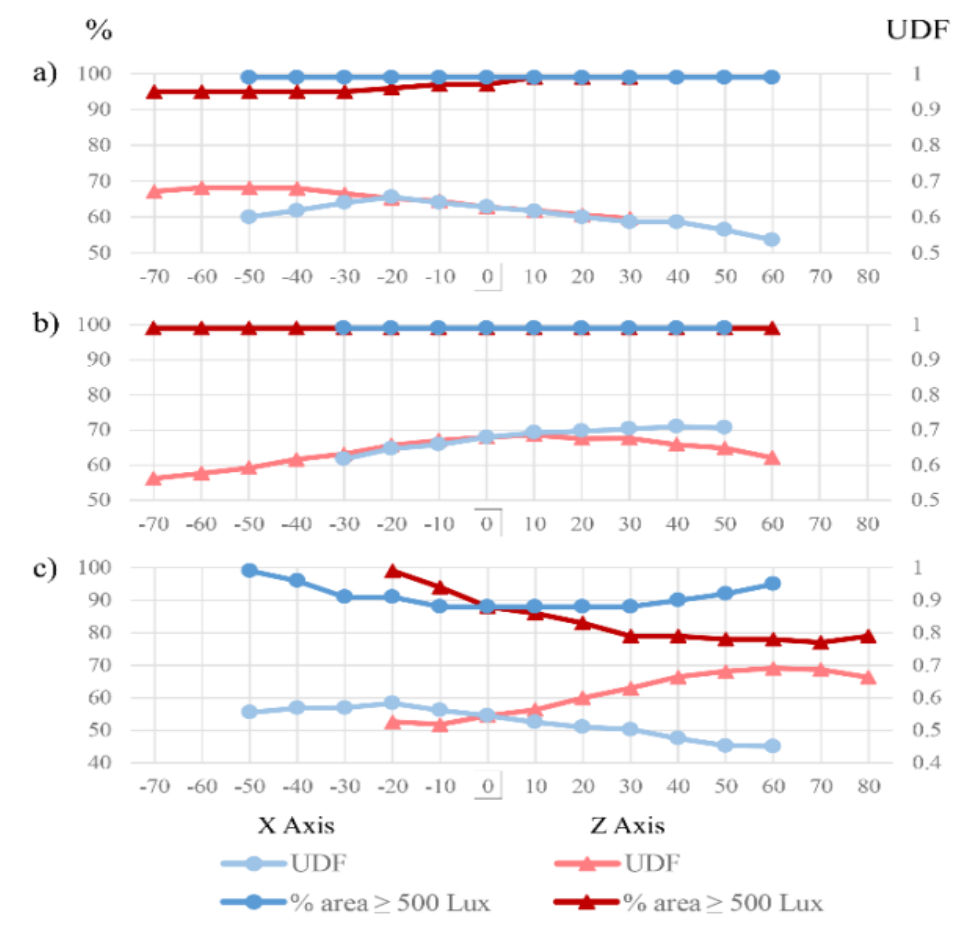

Figure 7: Lighting performance on September $21^{\text {st }}$ (a) 09:00 h, (b) 12:00 h, (c) 15:00 h.

the lowest natural lighting levels in the external environment. At 09:00 h, the reference configuration of the modules exhibits a decreased daylighting performance with a percentage of the plan of only $12 \%$ exceeding 500 Lux, although it achieves a relatively good daylighting distribution of 0.612 UDF. A further rotation of $+50^{\circ}$ in $\mathrm{Z}$ axis increases the lighting levels drastically at a $47 \%$ of the plan area exceeding 500 Lux, with an acceptable uniformity daylighting factor of 0.512 (fig. 3). Efficient daylighting performance is recorded at 12:00 h where the reference configuration exceeds 500 Lux for $77 \%$ of the plan and ensures uniformity daylighting factor UDF for $0.694 \%$. The most efficient condition is recorded at the arrangement of $-50^{\circ}$ rotation in $\mathrm{X}$ axis exceeding 500 Lux for $99 \%$ of the plan and uniformity daylighting factor UDF of 0.442 , a result which can be compared to lighting performances of the system during the brighter periods of the year. On the same day, at 15:00 h, the most efficient condition of the system is recorded at the arrangement of $+30^{\circ}$ rotation in $\mathrm{X}$ axis, recording a rather low percentage of the plan of $26 \%$ exceeding 500 Lux and a good daylighting distribution of $0.485 \mathrm{UDF}$. 


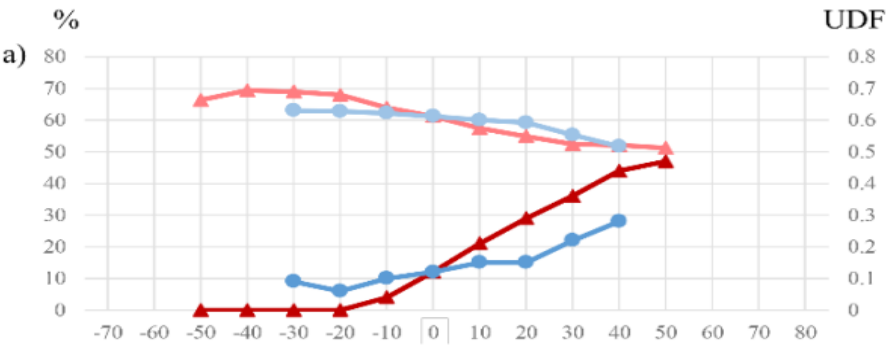

b) 100

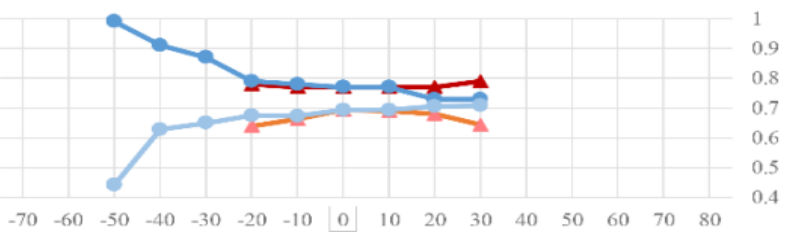

c) 80

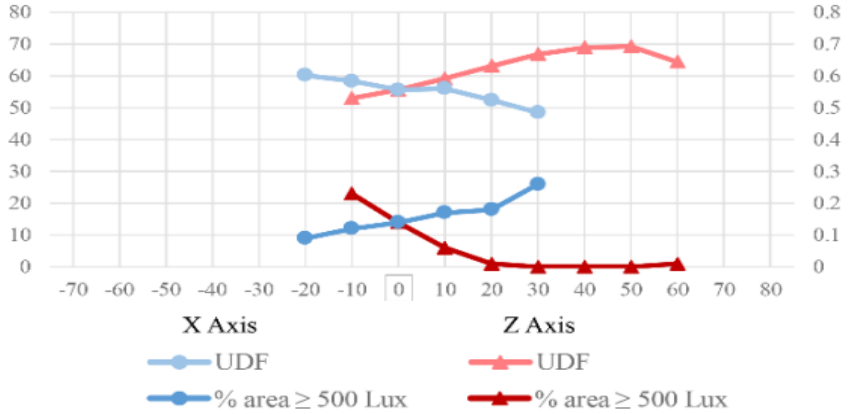

Figure 8: Lighting performance on December 21st (a) 09:00 h, (b) 12:00 h, (c) 15:00 h.

\section{Conclusion}

A control optimisation investigation of a modular lightweight adaptive façade system, to be applied as an alternative lighting renovation strategy for the agedbuilding stock in Europe, is demonstrated in the present paper. The parametrically defined kinetic model is examined in its enhanced controllability to improve the lighting conditions of a typical office space, based on comfortable lighting levels and uniform lighting distribution optimisation capabilities. The simulation concentrates on characteristic days of the year and hours of the day, in order to verify its adaptation performance on an annual basis. The results obtained reveal the ability of the system to both deliver appropriate conditions and stabilise the light-related objectives examined based on the evaluation criteria set. The applications of this methodology in diverse climate types and orientations will allow us to further evaluate the range of system's performance. Moreover, a future research may be oriented towards the technological optimisation of the system in order to ensure the ecological aspect of this approach as a renovation strategy. 


\section{References}

[1] Eurostat European Commission, Energy, transport and environment indicators 2012, Eurostat Pocketbooks, pp. 52-63, 2012.

[2] Buildings Performance Institute Europe. Europe's buildings under the microscope: A country-by-country review of the energy performance of buildings. Brussels, Belgium, 2011.

[3] Balaras, C.A. et al., Potential for energy conservation in apartment buildings. Energy and Buildings, 31, pp. 143-154, 2000.

[4] Michael, A., Natural Lighting in the Indoor Environment. ed. Méndez Vilas, A., Fuelling the Future: Advances in Science and Technologies for Energy Generation, Transmission \& Storage, BrownWalke Press, pp. 540-544, 2012.

[5] Michael, A., Eftychi, M., Pattichi E., Innovative integrated concept for an environmentally friendly and energy efficient building envelope. Proc. of the $10^{\text {th }}$ Int. Conf. On Advanced Building Skins, Bern, pp. 1360-1369, 2015.

[6] Palmero, A. I. \& Armando, C. O., Effect of louver shading devices on building energy requirements. Applied Energy, 87(6), pp. 2040-2049, 2010.

[7] Almussaed, A. \& Almssad, A., Natural lighting efficiency by means of sunskylight-tubes. International Journal of Engineering and Advanced Technology, 3(3), pp. 16-20, 2014.

[8] Beesley, P., et al., Responsive architectures: Subtle Technologies 2006. Riverside Architectural Press, 2006.

[9] Fox, M. A., Sustainable applications of intelligent kinetic systems. Proc. of the $2^{\text {nd }}$ Int. Conf. On Transportable Environments, Singapore, 2001.

[10] Michael, A., et al., Integration of a lightweight plug-in adaptive envelope to maximize performance of natural lighting of existing buildings. Proc. of the 10 ${ }^{\text {th }}$ Int. Conf. On Advanced Building Skins, Bern, pp. 1216-1225, 2015.

[11] Michael, A. \& Phocas, M.C., Construction Design and Sustainability in Architecture: Integrating Environmental Education into Architectural Studies, Journal of Renewable Energy \& Power Quality, 10, 2012.

[12] Markus, T.A. \& Morris, E.N., Buildings, Climate and Energy. Pitman, London, 1980.

[13] Buffoni G., Xuereb K., The Al Bahar Towers: shading, the real envelope. Proc. of the Int. Conf. On Building Envelope Design and Technology, Advanced Building Skins 2015, Graz, pp. 68-78, 2015.

[14] Tombazis, A.N., Passive cooling in the works of A.N. Tombazis and associates. Proc. of the Int. Conf. On Passive and Low Energy Cooling for the Built Environment, Santorini, Greece, 2005.

[15] ThyssenKrupp Quarter, www.thyssenkrupp.com.

[16] Milne, M. \& Givoni, B., Architectural Design Based on Climate. Energy Conservation through Building Design, McGraw-Hill, New York, 1979.

[17] Power, A., Does demolition or refurbishment of old and inefficient homes help to increase our environmental, social and economic viability? Energy Policy, 36(12), pp. 4487-4501, 2008.

[18] Iversen A. et al., Daylighting calculations in practice, Danish Building Research Institute. Aalborg University, Copenhagen, 2013. 